\title{
Managing and Analyzing Museum Environmental Data
}

\author{
Naoko Sonoda
}

\begin{abstract}
Two specially customized computer programs have been developed at the National Museum of Ethnology, Japan to facilitate the analysis of the museum environment: a pest monitoring data analysis program; and a temperature/relative humidity $(\mathrm{RH})$ monitoring data analysis program. These analysis programs improve understanding of the museum environment and support efficient and quick discovery of any abnormalities from a preventive conservation point of view. Daily and advanced uses of these data analysis programs were described. For example, a comparative study of the results of temperature and humidity control under the normal regime and under the power-saving regime was carried out based on actual readings, and permitted use of more energy-efficient air-conditioning control since FY2014. For the next development, it is intended to incorporate these analytical programs into "data analysis small packages" that can be used freely by other museums and related institutions.
\end{abstract}

\section{Introduction}

In this time of globalization, the role of museums in valuing tangible cultural heritage from different communities or nations, through ensuring broader access to the collections while managing their proper conservation, is gaining importance. With increasing demand of access to the collection, museums need to take good balance between access and conservation.

At the same time, the museums of the twenty-first century are required to pay consideration to its environmental impact. Two important environmental issues affecting museums are protection of the ozone layer, and climate change. The former led to a comprehensive review of policies regarding the use of chemical fumigants on cultural properties in Japan, resulting in the implementation of Integrated Pest Management (IPM). Climate change affects not only the outdoor environment but also the museum environment. We face to a dilemma how to reduce the energy consumption without generating an adverse effect to climate control within a museum.

\footnotetext{
N. Sonoda $(\bowtie)$

National Museum of Ethnology, Senri Expo Park, Suita, Osaka 565-8511, Japan

e-mail: sonoda@idc.minpaku.ac.jp 
Moreover, in Japan, energy saving becomes a serious matter after the Great East Japan Earthquake occurred in 2011.

Considering that museum collections and especially those in a museum of ethnology are frequently composed of organic materials susceptible to insect and fungal attacks, control of the museum environment is an important task. Each museum is taking action for sustainable museum environment control based on the results of museum environment investigations. Among these investigations, a huge amount of data has to be handled for pest monitoring and temperature/relative humidity (RH) monitoring. A key point is how to analyze these data effectively and efficiently from a conservation point of view. For this purpose, two specially customized computer programs have been developed at the National Museum of Ethnology, Japan in order to facilitate the analysis of the museum environment: a pest monitoring data analysis program and a temperature/RH monitoring data analysis program. These analysis programs contribute to improve understanding of the actual state of the museum environment and to find out efficiently and quickly any abnormalities from a preventive conservation point of view. Based on this, a new development is ongoing at the National Museum of Ethnology, Japan to improve these analysis programs into museum environment "analysis small packages" that can be used free of charge by any other institution.

This paper first describes examples of computer-assisted analysis of the museum environment performed at the National Museum of Ethnology, Japan and then describes briefly the ongoing development of the analysis programs.

\section{Pest Monitoring Data Analysis}

As a part of the efforts to implement IPM, pest monitoring using insect traps has been ongoing since 1992 at the National Museum of Ethnology, Japan. Two kinds of insect traps (327 sheet traps and 181 pheromone traps for cigarette beetles) are set at fixed points in different parts of the museum including the storage zone, the gallery zone and the other zone for 2 weeks and then collected. The pests captured in each trap are then counted and identified. The results are collected on a Microsoft Excel sheet in which the pest species damaging the museum collection and captured so far in our museum are figured (Table 1).

\subsection{Daily Use}

The pest monitoring data analysis program is currently used to make different graphs (line graphs or bar graphs) and traps mapping.

After each seasonal investigation, the newly acquired data are checked systematically through comparison with data from the same season of the previous years; this is in order to judge whether the current situation is normal or not. If any problem 
Table 1 Pest list used at the National Museum of Ethnology, Japan for monitoring pests

\begin{tabular}{|c|c|}
\hline \multirow[t]{20}{*}{ Coleoptera (Beetle, Weevil) } & Anthrenus verbasci \\
\hline & Attagenus japonicus Reitter \\
\hline & Other Dermestidae* \\
\hline & Dinoderus minutus (Fabricius) \\
\hline & Other Bostrychidae* \\
\hline & Lyctus brunneus (Stephens) \\
\hline & Other Lyctidae* \\
\hline & Stegobium paniceum (Linnaeus) \\
\hline & Lasioderma serricorne (Fabricius) \\
\hline & Other Anobiidae* \\
\hline & Ptinidae \\
\hline & Sitophilus zeamais \\
\hline & Other Rhynchophoridae (added in April, 2007) \\
\hline & Tribolium castaneum \\
\hline & Other Tenebrionidae \\
\hline & Curculionoidea \\
\hline & Oryzaephilus surinamensis \\
\hline & Other Silvanidae \\
\hline & Cerambycidae* \\
\hline & Other Coleoptera $^{*}$ \\
\hline \multirow[t]{4}{*}{ Lepidoptera (Moth and Butterfly) } & Tinea translucens Meyrick \\
\hline & Tineola bisselliella \\
\hline & Pyralidae \\
\hline & Other Lepidoptera* \\
\hline \multirow[t]{4}{*}{ Blattaria (Cockroach) } & Periplaneta fuliginosa (Serville) \\
\hline & Periplaneta americana (Linnaeus) \\
\hline & Blattella germanica (Linnaeus) \\
\hline & Other Blattaria \\
\hline \multirow[t]{2}{*}{ Thysanura (Bristle teil) } & Ctenolepisma villosa (Fabricius) \\
\hline & Other Thysanura* \\
\hline \multirow[t]{2}{*}{ Psocoptera (Booklouse) } & Liposcelidae \\
\hline & Other Psocoptera* \\
\hline \multirow[t]{3}{*}{ Orthoptera (Orthopteron) } & Rhaphidophoridae \\
\hline & Gryllidae \\
\hline & Other Orthoptera \\
\hline \multirow[t]{2}{*}{ Isoptera (Termite, White ant) } & Reticulitermes speratus (Kolbe) \\
\hline & Other Isoptera $^{*}$ \\
\hline \multirow[t]{3}{*}{ Diptera (Fly) } & Diptera, orinigated from inside (added in July, 2008) \\
\hline & Diptera, originated from outside (added in July, 2008) \\
\hline & Other Diptera or all Diptera before July 2008 \\
\hline \multirow[t]{2}{*}{ Hymenoptera (Sawfly, Wasp, Bee, Ant) } & Formicidae $^{*}$ \\
\hline & Other Hymenoptera \\
\hline
\end{tabular}


Table 1 (continued)

\begin{tabular}{l|l}
\hline Thysanoptera (Thrip) & All Thysanoptera \\
\hline \multirow{2}{*}{ Hemiptera (Truebug) } & Heteroptera \\
\cline { 2 - 2 } & Aphidoidea \\
\cline { 2 - 2 } & Cicadellidae \\
\cline { 2 - 2 } & Homoptera \\
\cline { 2 - 2 } & Psylloidea \\
\cline { 2 - 2 } & Other Hemiptera \\
\hline Collembola (Springtail) & All Collembola \\
\hline Dermaptera (Earwig) & All Dermaptera \\
\hline Other Insecta & All other Insecta (added in April, 2007) \\
\hline Arachnida/Acari (Mite, Tick) & All Acari \\
\hline Arachnida/Araneae (Spider) & All Araneae \\
\hline $\begin{array}{l}\text { Malacostraca/Isopoda } \\
\text { (Woodlouse, Pill bug) }\end{array}$ & All Isopoda \\
\hline Diplopoda (Millipede) & \\
\hline Chilopoda (Centipede) & All Diplopoda \\
\hline Others & All Chilopoda \\
\hline
\end{tabular}

*If found, species should be specified

is discovered, the possible causes of the abnormalities are to be clarified through an in-situ inspection by museum staff and necessary measures taken.

The original traps mapping program based on Microsoft Excel is an effective tool to visualize the geographic concentration of the pests as well as the distribution of the pest species. As an example, the traps mapping of the results of our investigation in winter 2015 is given in Fig. 1.

- The geographic concentration of the pests is presented; the darker the color, the more concentrated the number of the pests captured. We remark that a very few pests are captured in the storage zone (dark gray area).

- From the distribution of the pest species, we observe that pests trapped in the other zone (light gray area) are mostly flies in the corridors near the shutter doors $(\vec{\square})$.

\subsection{Advanced Use}

A review of the data accumulated since 1992 contributes to understand the pest trends in the museum (Sonoda and Hidaka 2011).

- Pests are most frequently captured in summer, followed in order by spring, autumn, and winter. There are no clear seasonal characteristic in the species captured, probably because the museum environment is controlled for human 


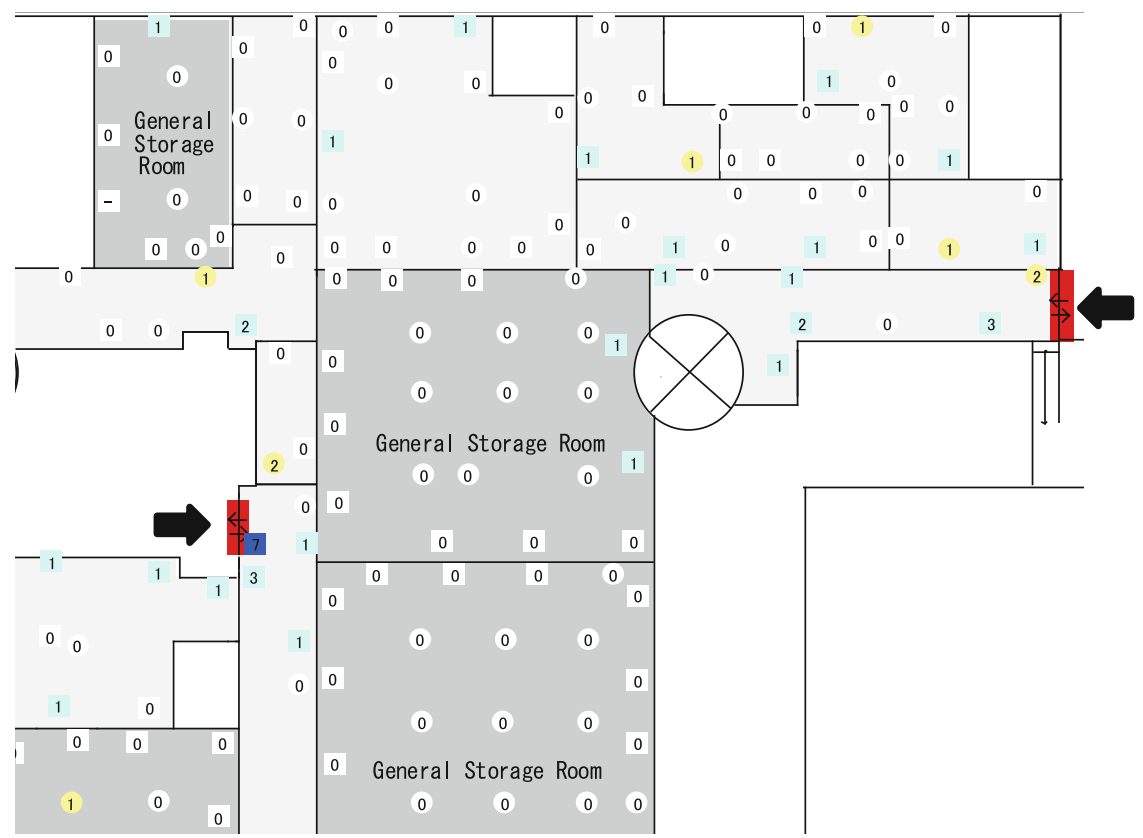

Geographic concentration of the pests: the total number of the pests captured in each trap (upper)

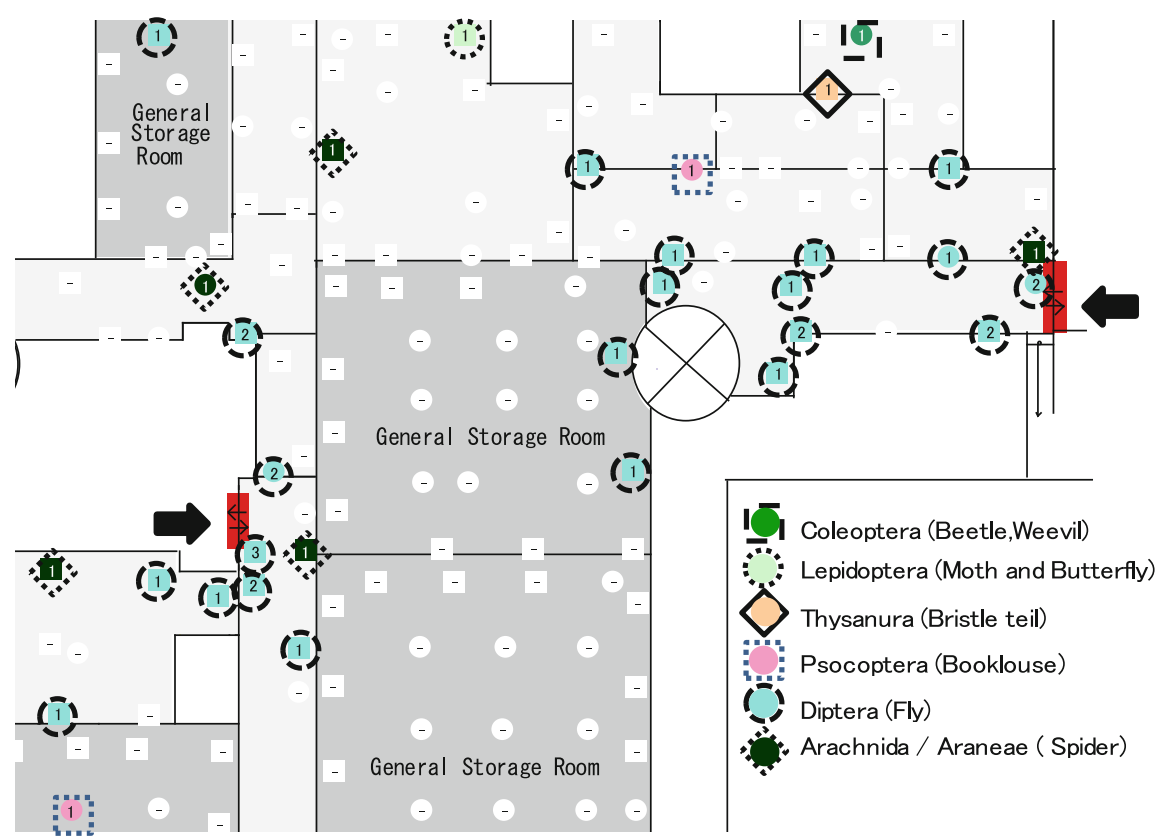

Distribution of the pest species: the most captured pest species in each trap (lower)

Fig. 1 Traps mapping: Geographic concentration of the pests (upper) and distribution of the pest species (lower) from the results of the investigation winter 2015. Dark gray area: storage zone Light gray area: other zone. $\square$ Sheet traps $\bigcirc$ Pheromone traps 


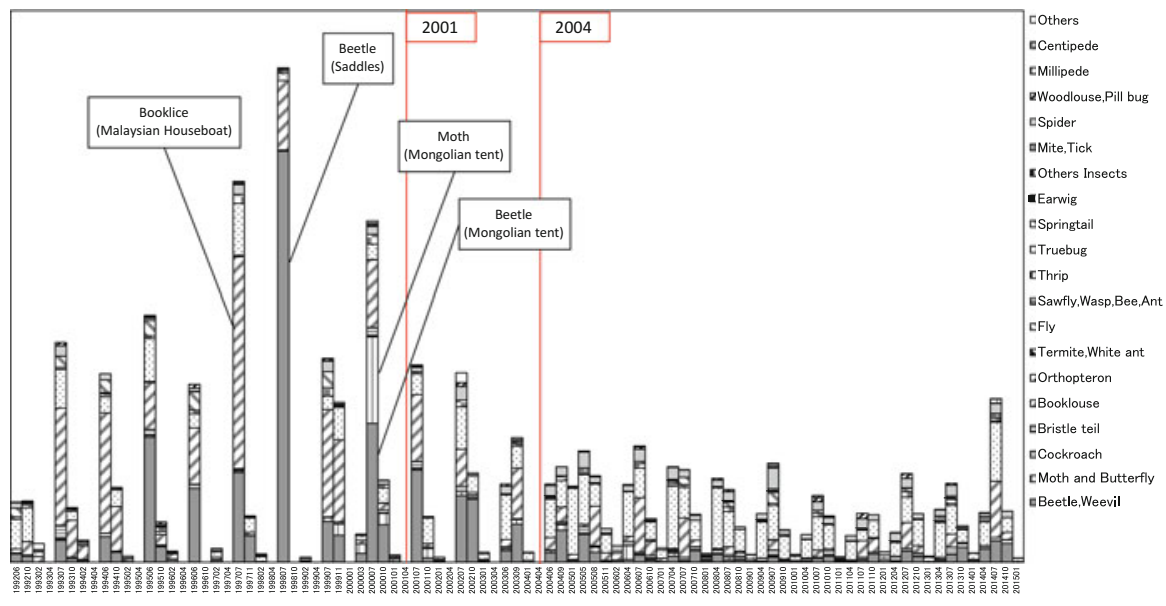

Fig. 2 Relative changes in the numbers of pests trapped in the gallery zone from 1992 to 2015

comfort and consequently for pest comfort throughout the year. In the storage zone, constant attention should be paid to booklice, beetles and moths. In the gallery and other zones, pests originating from outside the museum are frequently captured: flies in all seasons; spiders in spring and winter, and woodlice in summer and autumn. Booklice always rank among the most frequently captured species, except in the gallery and other zones in spring, which is a dry season in Osaka (where the National Museum of Ethnology, Japan is located).

- In the period 1992-1999, the most frequently captured species were booklice and beetles, the latter becoming more prevalent around 1997-1999. Between 1999 and 2000, there was a local outbreak of moth, and from 2001 a marked increase in flies. At the beginning of the investigation, booklice were found mainly in the storage and gallery zones, yet are now observed mainly in the other zone. Beetles are captured mainly in the storage and gallery zones, although their numbers have clearly decreased in recent years. Moths were found almost exclusively in the storage zone in 1999-2000, during work to replace air conditioning ducts. Flies have appeared frequently in the other zone since 2001. The occurrence of pests has changed location from the storage and gallery zones to the other zone; this change occurred in 2001 when we started to strengthen communication between different sections based on the principles of IPM.

- In the gallery zone, there is a clear tendency for pin-point attacks. Some objects such as a houseboat in the Southeast Asia gallery and a Mongolian tent in the North Asia gallery have been suffering regularly from pest attacks. This observation led us, in 2004, to introduce an IPM inspection (visual observation of the objects most prone to pest/fungus attacks) at the time of the daily rounds in the exhibition galleries before the museum opens. Figure 2 shows relative changes in the number of pests trapped in the gallery zone from 1992 to 2015, indicating that the situation improved on two occasions, in 2001 and in 2004. The former is 
the date on which we started to strengthen communication between different sections as noted above, thus confirming the importance of better communication and daily attention.

- In the storage zone, pest attacks tend to spread. This can be attributed to the density of the objects in the storage zone. Another possible reason is that, in the storage zone, in comparison with the gallery zone, the objects are not exposed to human eyes as often, thus preventing early detection. Therefore, it was decided that different storage rooms be cleaned regularly, finishing with a rapid IPM inspection of all the objects stored in the respective rooms. In this way, each room is cleaned and each object is given a cursory inspection at least once a year.

\section{Temperature/RH Monitoring Data Analysis}

Monitoring temperature and RH with data loggers started in 2004, to complement the classical monitoring using thermo-hydrographs. Currently, nearly 150 data loggers are used mainly covering the storage zone and the gallery zone. As of January 2015, we have accumulated $26 \mathrm{~GB}$ of data in our temperature and RH database.

\subsection{Daily Use}

Temperature and RH data are checked sequentially by the central surveillance center and necessary measures taken as the need arises. Data are solely reviewed every 2 weeks and shared between museum staff of different sections. Every month, the newly acquired data are presented in graphs using the temperature/RH monitoring data analysis program and checked in order to judge whether the current situation is normal or not. If any problem is discovered, the possible causes of the abnormalities are to be clarified and necessary measures taken.

\subsection{Advanced Use}

In order to overcome the electricity shortage due to the Great East Japan Earthquake of March 2011, 10-15\% reduction in electricity use (in comparison with 2010) was requested in winter 2011 and in summer 2012, leading us to adopt a power-saving regime for several general storage rooms.

The storage rooms at the National Museum of Ethnology, Japan are divided into two types: general storage rooms and special storage rooms. Most of the items in the museum collections are made of composed materials and are placed in general storage rooms under collection classifications, without any sorting by material. Special storage rooms house artifacts made of sensitive materials requiring finely tuned air-conditioning control, as well as items which require special security arrangements. 
Table 2 Temperature and RH settings under the normal, power-saving, and new regimes for general storage rooms

\begin{tabular}{|c|c|c|c|c|}
\hline & Spring & Summer & Autumn & Winter \\
\hline \multirow[t]{3}{*}{$\begin{array}{l}\text { NORMAL } \\
\text { regime }\end{array}$} & $\begin{array}{l}\text { Adjustments } \\
\text { made in } \\
\text { increments of } \\
0.5^{\circ} \mathrm{C} / \text { week }\end{array}$ & $26 \pm 2{ }^{\circ} \mathrm{C}$ & $\begin{array}{l}\text { Adjustments } \\
\text { made in } \\
\text { decrements of } \\
0.5^{\circ} \mathrm{C} / \text { week }\end{array}$ & $20 \pm 2{ }^{\circ} \mathrm{C}$ \\
\hline & \multicolumn{4}{|l|}{$52 \pm 5 \% \mathrm{RH}$} \\
\hline & \multicolumn{4}{|l|}{$8: 20-18: 00$} \\
\hline \multirow{3}{*}{$\begin{array}{l}\text { POWER } \\
\text { SAVING } \\
\text { regime }\end{array}$} & \multirow[t]{3}{*}{ OFF } & $26 \pm 2{ }^{\circ} \mathrm{C}$ & \multirow[t]{3}{*}{ OFF } & $20 \pm 2^{\circ} \mathrm{C}$ \\
\hline & & $52 \pm 5 \% \mathrm{RH}$ & & $52 \pm 5 \% \mathrm{RH}$ \\
\hline & & $\begin{array}{l}\text { Only Wednesdays } \\
\text { and Sundays }\end{array}$ & & $\begin{array}{l}3-4 \mathrm{~h} \text { at night } \\
\text { everyday }\end{array}$ \\
\hline \multirow{4}{*}{$\begin{array}{l}\text { NEW regime } \\
\text { since FY2014 }\end{array}$} & \multirow[t]{4}{*}{ OFF } & $26 \pm 2{ }^{\circ} \mathrm{C}$ & \multirow[t]{4}{*}{ OFF } & $20 \pm 2{ }^{\circ} \mathrm{C}$ \\
\hline & & $52 \pm 5 \% \mathrm{RH}$ & & $52 \pm 5 \% \mathrm{RH}$ \\
\hline & & $8: 20-18: 00$ & & $8: 20-18: 00$ \\
\hline & & $\begin{array}{l}\text { Air conditioning } \\
\text { starts when } \\
\text { temperature }>25 \\
{ }^{\circ} \mathrm{C} \text { or }>65 \% \mathrm{RH} \\
\text { for more than one } \\
\text { week }\end{array}$ & & $\begin{array}{l}\text { Air conditioning } \\
\text { starts when } \\
\text { temperature is too } \\
\text { cool for museum } \\
\text { staff to work or } \\
<40 \% \text { RH }\end{array}$ \\
\hline
\end{tabular}

Before the power-saving regime (normal regime), the general storage rooms were air-conditioned daily between 08:20 and 18:00. The temperature was set at $26 \pm 2{ }^{\circ} \mathrm{C}$ in summer and at $20 \pm 2{ }^{\circ} \mathrm{C}$ in winter, varying $0.5^{\circ} \mathrm{C}$ per week in the transitional periods, while $\mathrm{RH}$ was set at $52 \pm 5 \%$ all the year. The power-saving regime was adopted for general storage rooms. Under the power-saving regime, the airconditioning was turned off during the transitional periods. During the winter of 2011, air-conditioning was run only at night during the off-peak period. In summer 2012, air-conditioning was only run for 24 h, 2 days a week (Table 2). However, one of the general storage rooms (Room No. 5) was exempted from these power-saving measures as it was situated in upstairs and not surrounded by other rooms. Consequently this room is easily exposed to the effects of outside air.

The results of temperature and humidity control under the normal regime and the power-saving regime were examined and compared based on actual readings (Sonoda and Hidaka 2013).

- For the transition periods, temperature changes occurred more gradually with the suspension of air-condition under the power-saving regime than under the normal regime, resulting in smaller fluctuations in temperature and in $\mathrm{RH}$.

- Under the normal regime, the average temperature remained within the control range in all of the storage rooms, whereas it tended to drop below the control range under the power-saving regime. The maximum daily difference between the lowest and the highest temperature readings was less than $4{ }^{\circ} \mathrm{C}$ (even less than $2{ }^{\circ} \mathrm{C}$ in several rooms) under both regimes, except in Room No.5. The average daily difference was around $2{ }^{\circ} \mathrm{C}$ or less (even less than $0.5^{\circ} \mathrm{C}$ in several rooms) under both regimes, except in Room No.5. 
- The average RH was slightly higher during the summer period under the powersaving regime (around $60 \% \mathrm{RH}$ ) but otherwise remained largely within the control range. The maximum daily difference in RH was $10 \% \mathrm{RH}$ or less under both regimes in most storage rooms, but in some storage rooms this value exceeded $10 \% \mathrm{RH}$ during spring and summer. The average daily difference in RH was less than $5 \% \mathrm{RH}$ under both regimes except the summer period under the normal regime where it exceeded this value.

- No significant difference between the two regimes was observed in the annual temperature difference. The annual RH difference was greater under the powersaving regime than under the normal regime. However, weekly transition in temperature and in RH was comparable under both regimes except the summer period under the power-saving regime where greater temperature and $\mathrm{RH}$ fluctuations were observed.

From all these observations, it was concluded that the temperature and humidity control level was acceptable under both regimes except the summer period under the power-saving regime. This study resulted in the adoption of energy-efficient airconditioning control (the new regime) since fiscal year 2014 (Table 2). Under the new regime, air-conditioning is switched off in spring and autumn, and starts when the temperature or RH values become too high in summer or too low in winter. If the power-saving regime is requested, we opt to reduce the air-conditioning time by running the air-conditioning for just a short period every day and not by alternating between no-air-conditioning days and 24-h-operation days in order to avoid temperature and humidity fluctuations.

Figure 3 compares actual data from one of the general storage rooms under the normal, power-saving, and new regimes.

- For spring and autumn, temperature changes occurred more gradually with the suspension of air-conditioning under the power-saving regime and the new regime (-je than under the normal regime, resulting in smaller daily fluctuations in temperature and in $\mathrm{RH}$.

- After a period of no air-conditioning in spring 2014, the temperatures in the storage rooms were actually lower than the temperature setting of the air-conditioning on the day the air-conditioning was scheduled to be switched on, and this allowed the use of air-conditioning to be delayed ( $\square$ ).

- At the beginning of December 2014, several museum staff felt that the temperature was becoming too cold. We started air-conditioning 1 week earlier than the

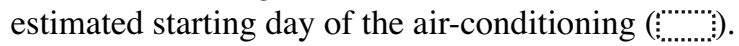

- The above two observations led us to conclude that the suspension of airconditioning in the transition periods may allow the use of air-conditioning to be delayed, but this depends on the outside climate at the time.

Figure 4 compares the weekly distributions in temperature and $\mathrm{RH}$ for each season for the same general storage room as in Fig. 3. An ellipse was drawn for each week to include $90 \%$ of the data. The size of each ellipse reflects the fluctuation; the greater the size, the greater the weekly fluctuation in temperature and/or RH. The idea for this ellipse analysis came from a previous study done in our museum (Morita 1981). 
Spring

Summer

Autumn

Winter

NORMAL regime (April 2010-March 2011)
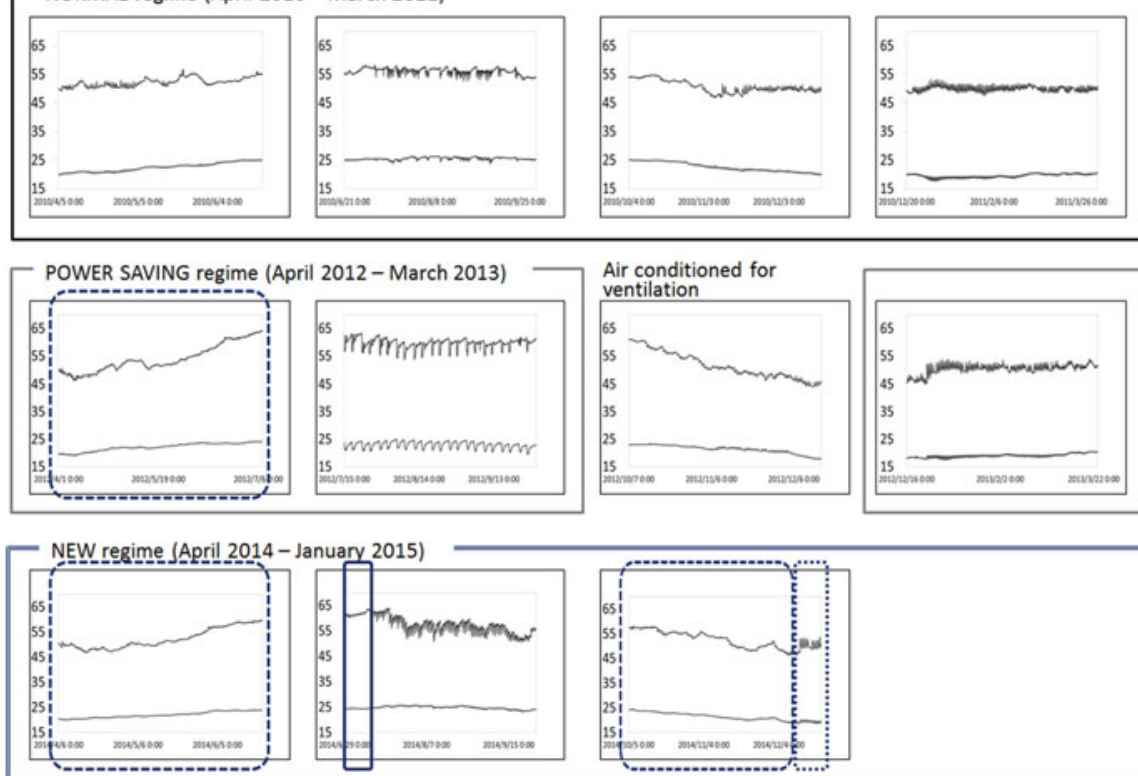

Fig. 3 Annual data from one of the general storage rooms under the normal (upper), power-saving (middle), and new (lower) regimes. Upper lines: relative humidity (\%RH). Lower lines: temperature $\left({ }^{\circ} \mathrm{C}\right)$

- At the weekly level, fluctuations were comparable and acceptable under the different regimes for the transition periods of spring and autumn as well as for winter, as shown by the similar small sizes of the ellipses.

- In summer however, much greater ellipses were observed under the power-saving regime, suggesting bigger temperature and RH fluctuations ( $\square$ ).

Overall, we estimate that, except for the summer period under the power-saving regime, there were no sudden fluctuations in temperature and $\mathrm{RH}$, and weekly transitions in temperature and in RH were more or less comparable under the three regimes.

\section{Future Development}

As the next development, we plan to develop these data analysis programs (pest monitoring data analysis program, and temperature/RH monitoring data analysis program) and to make "data analysis small packages" that can be used free of charge by any other institution. We are at the stage of making further program changes and 


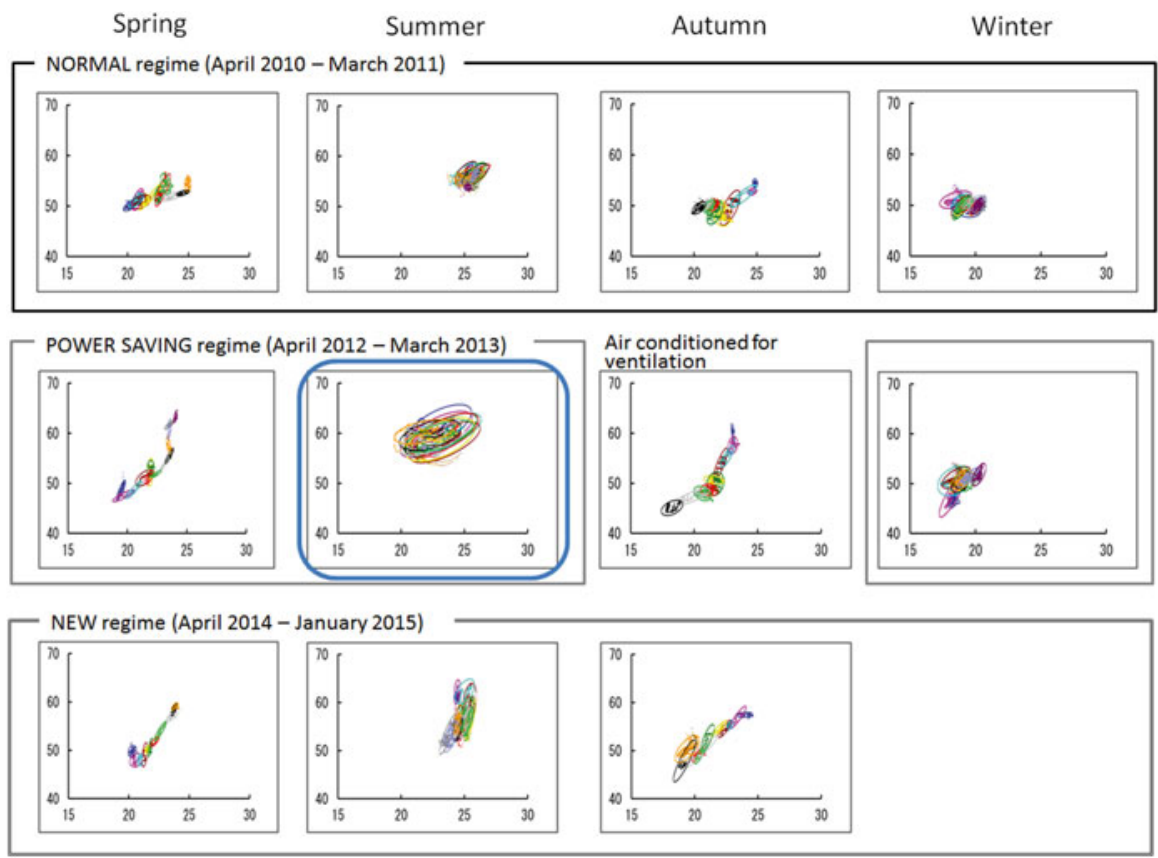

Fig. 4 Weekly distributions in temperature and in RH for each season for the same general storage room as in Fig. 3 under the normal (upper), power-saving (middle), and new (lower) regimes. $X$ axis: temperature $\left({ }^{\circ} \mathrm{C}\right) . Y$ axis: relative humidity $(\% \mathrm{RH})$

improvement, after having received comments and requests by researchers who kindly had accepted to use the prototype version of the "temperature/RH monitoring data analysis small package." We hope that the Japanese version will be available in the near future. The English one is in the planning stage.

Both the "pest monitoring data analysis small package" and "temperature/RH monitoring data analysis small package" are conceived on the same principles: simple and easy for anyone to use without receiving any special training. The systems required for these data analysis small packages are: Windows 8 (64 bits) or Windows 8.1 (64 bits); CPU Intel Core i5; memory 4 GB; Microsoft Excel 2010 (64 bits); and disk capacity of more than $500 \mathrm{~GB}$.

The starting window contains six tool buttons (Fig. 5):

- The "Data Fetching" button is used to go to a data fetching window.

- The "Graphs Making" button is used to go to a graph and/or mapping setting window.

- In the case of pest monitoring data analysis, we have a choice between graphs making and maps making. Graphs can be chosen between bar graphs and line graphs. Maps are of two sorts: geographic concentration of the pests; and distribution of the pest species. 


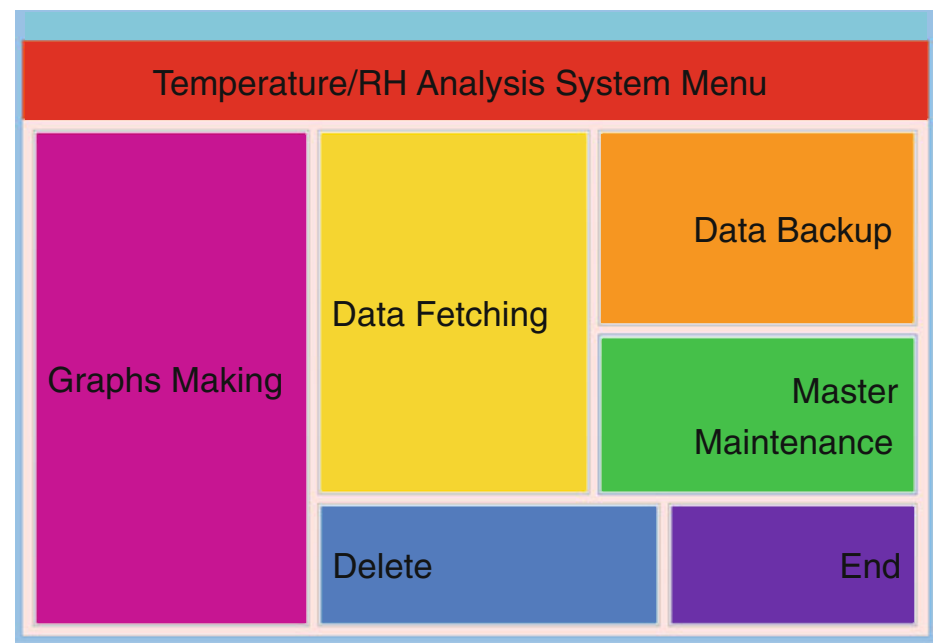

Fig. 5 Starting window of the temperature/RH data analysis small package (image)

- In the case of temperature/RH monitoring data analysis, we can select either graphs making or temperature/RH distribution maps. Graphs can be drawn for temperature, for $\mathrm{RH}$, or for both. For temperature/RH distribution maps, each data is presented as an intersection of temperature ( $\mathrm{X}$ axis) and $\mathrm{RH}$ ( $\mathrm{Y}$ axis). An ellipse can be drawn to insert $90 \%$ of data, and thus it becomes easy to find out the abnormal data.

- "Master Maintenance" is used to go to a master maintenance window. It allows the registration of the master information, such as the geographic information and the pest species list.

- The geographic information is given using three levels: in case of National Museum of Ethnology, Japan, the first and the biggest level is "Zone" (such as the storage zone, the exhibition zone, and the other zone), each zone is divided into the second level "Room". In each room, we have the third and the lowest level corresponding to each trap. It is up to the user to select the three levels, for example, the others may choose building as the first level, floor as the second level, and trap as the third level.

- The species list is classified using two levels: the first level "Order" is divided into the second level "Family, Species".

- "Data Backup" is used to go to a data backup window.

- The "Delete" button is used to go to a delete window from which we can delete acquired data.

- The "End" button is used to end the program.

- From each window, we just need to follow and check the instructions one by one. It is designed to be used instinctively. 


\section{Conclusion}

Two specially customized analysis programs (pest monitoring data analysis program and temperature/RH monitoring data analysis program) have been developed at the National Museum of Ethnology, Japan for the analysis of the museum environment, and some concrete examples of use and application in our museum were shown. As the next development, we intend to improve these analysis programs into "Data analysis small packages" that can be used free of charge by other museums or related institutions. The Japanese version will be available in the near future and the English one is in the planning stage.

It goes without saying that the development of the analysis programs and that of the "analysis small packages" are not the sole aim in itself. These computer-assisted analyses are just a tool for giving insight into general trends, highlighting deficient areas of the museum from the viewpoint of museum environment control, facilitating further analysis of the museum environment, and helping us in decision-making for a short- to long-term collection management strategy. They are certainly of some help especially when dealing with a huge amount of data. However, the most important thing is what we do, after obtaining the analysis results, in order to improve the museum environment.

Open Access This chapter is distributed under the terms of the Creative Commons AttributionNonCommercial 4.0 International License (http://creativecommons.org/licenses/by-nc/4.0/), which permits any noncommercial use, duplication, adaptation, distribution and reproduction in any medium or format, as long as you give appropriate credit to the original author(s) and the source, provide a link to the Creative Commons license and indicate if changes were made.

The images or other third party material in this chapter are included in the work's Creative Commons license, unless indicated otherwise in the credit line; if such material is not included in the work's Creative Commons license and the respective action is not permitted by statutory regulation, users will need to obtain permission from the license holder to duplicate, adapt or reproduce the material.

\section{References}

Morita, Tsyuneyuki. 1981. Microclimatic conditions within the National Museum of Ethnology. Bulletin of the National Museum of Ethnology 6(1): 159-182. (In Japanese with an abstract in English).

Sonoda, Naoko, and Hidaka, Shingo. 2011. Integrated pest management at the National Museum of Ethnology, Japan: Re-evaluation of preventive measures and control strategies. In Integrated pest management for collections. Proceedings of 2011: A Pest Odyssey, 10 Years Later. London, 26-28 October 2011, ed. Peter Winsor, David Pinniger, Louise Bacon, Bob Child, Kerren Harris, Dee Lauder, Julie Phippard and Amber Xavier-Rowe, 123-138. Swindon: English Heritage.

Sonoda, Naoko, and Hidaka, Shingo. (Oral communication). Sustainable and environmental friendly museum environment: A case study from the National Museum of Ethnology after the Great East Japan Earthquake. In Cultural heritage conservation science and sustainable development: experience, research, innovation, International conference in the frame of the 50th anniversary of the Centre de recherche sur la conservation des collections. Paris, 23-25 Oct 2013. 